$T$ ID-4500, UC-35

Nuclear Explosions -

Peaceful Applications

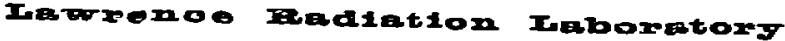 \\ UHIVESITY OF CALIFORALIA \\ LIVERUORE
}

\section{DCRL-50939 \\ A COMPUTER CODE FOR THE ANALYSIS OF DIGITIZED SEISMIC SIGNAIS \\ Barry C. Howard}

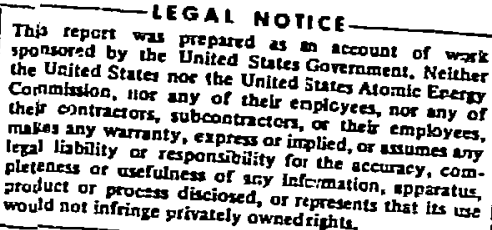




\section{Contents}

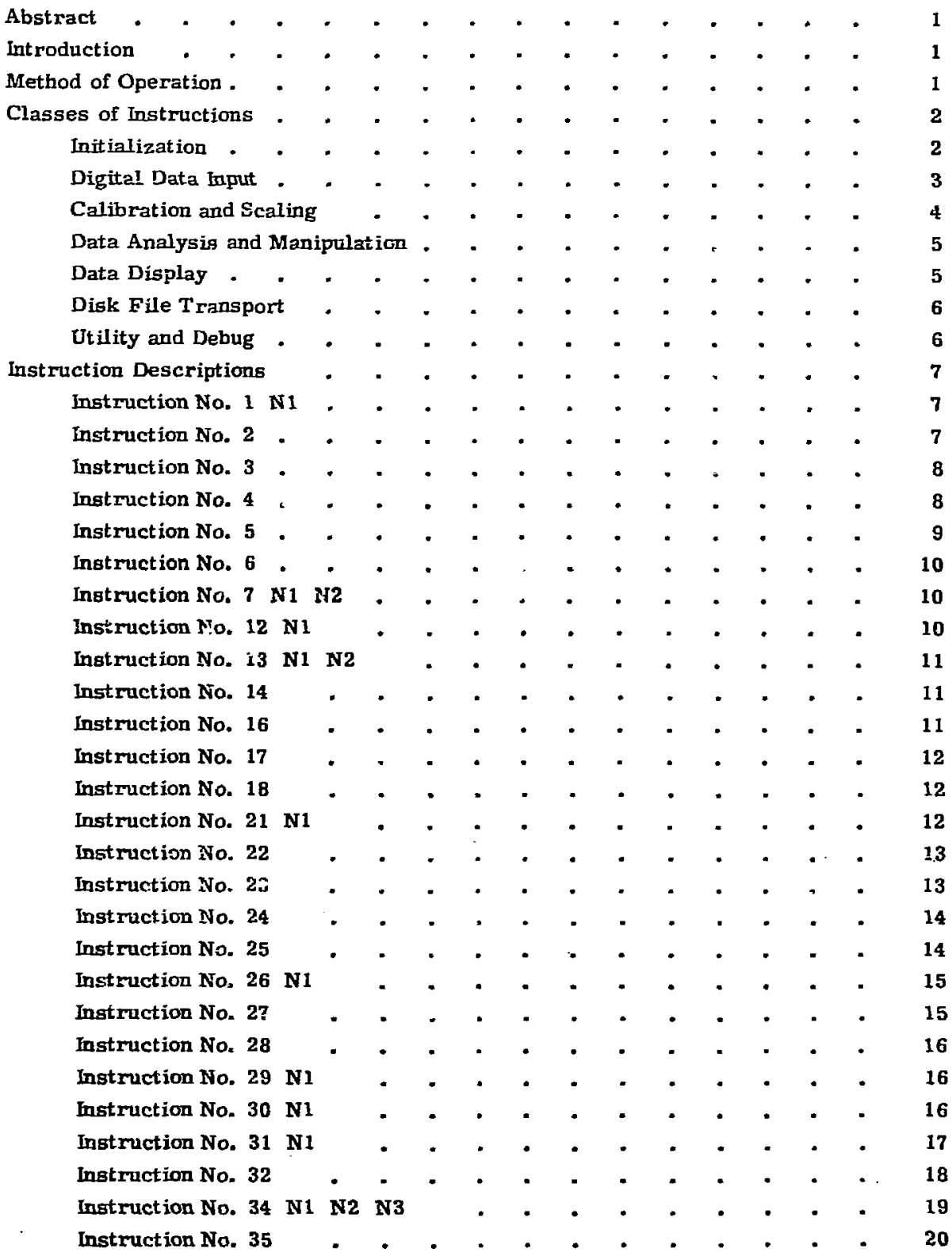


Instruction Descriptions (continued)

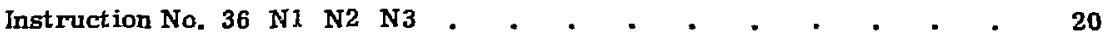

Instruction No. $37 \mathrm{~N} 1 \mathrm{~N} 2 \mathrm{N3}$. $\quad . \quad . \quad . \quad . \quad . \quad . \quad . \quad . \quad . \quad 2 \mathrm{I}$

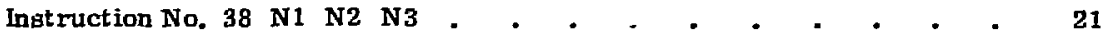

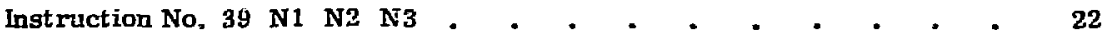

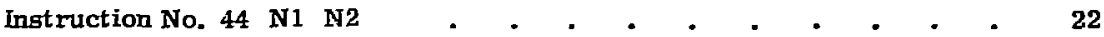

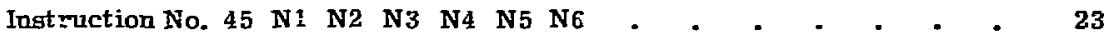

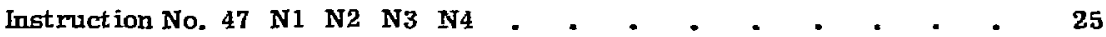

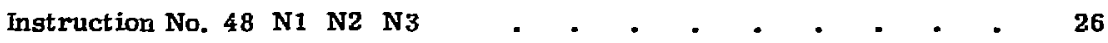

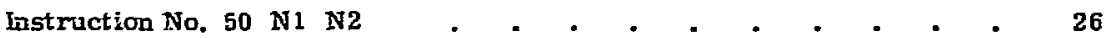

Instruction No. $53 \mathrm{~N} 1 \quad$ - . . . . . . . . . . . . . 27

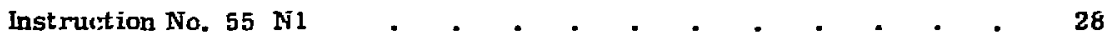

Instruction No. 56 N1 N2 $\quad$ - . . . . . . . - . . . . . 28

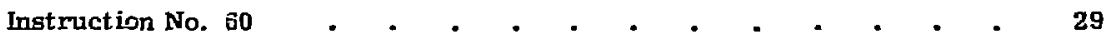

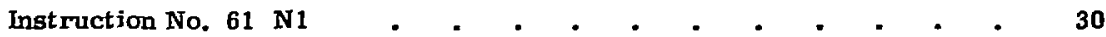

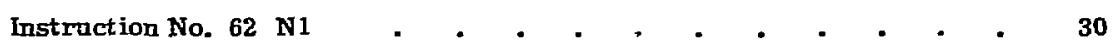

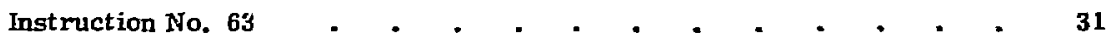

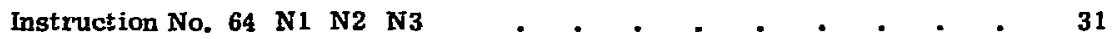

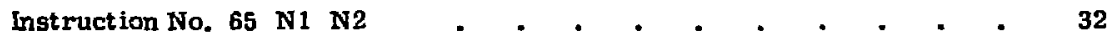

Instruction No. 66 N1 N2 N3 N4 N5 . . . . . . . . . . 32

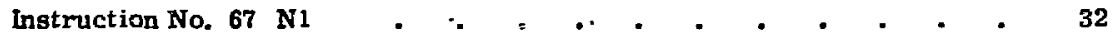

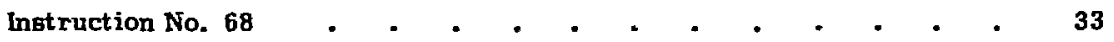

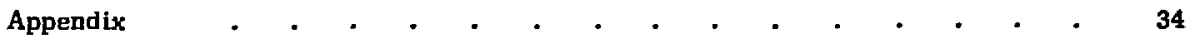

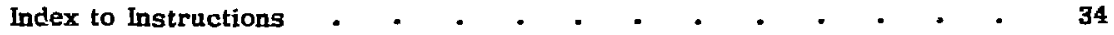

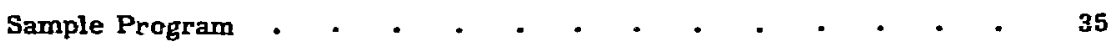

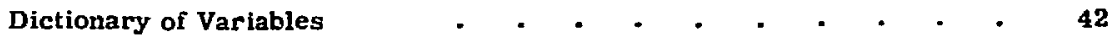

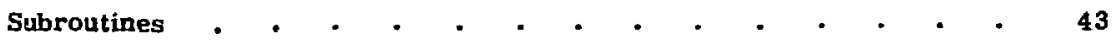

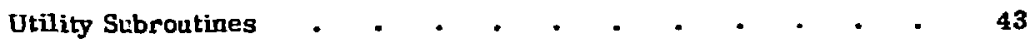

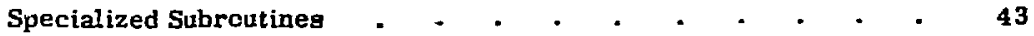

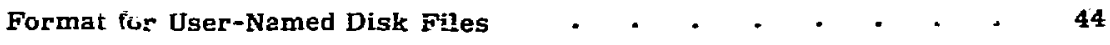




\title{
A COMPUTER CODE FOR THE ANALYSIS OF DIGITIZED SEISMIC SIGNALS
}

\begin{abstract}
The ADSS code, a multipurpose tool for the reduction of digitized seismic signal data, is presented. The 48 major functions of the code, subreutines identified and calied by number, are described. A sample application of the program to digitized seismic data is included. This paper can serve both as an introduction and as a reference manual for the ADSS code.
\end{abstract}

\section{Introduction}

The ADSS computer code in basically a modified version of the A/D 6600 ("SNORTER") code written by David Schreiber and Robert Veilleux." This latter code is a multipurpose program used for the reduction of digitized data produced by the $W$ Division Data Reduction Center at Lawrence Radiation Laboratory, Livermore. The adaptation of the A/D 6600 code to the problern of analyzing digitized seismic signals, with the addition of certain capabilities, has prcduced the present form of ine ADSS code.

The structure of the ADSS program allows much versatility it its application. It is essentially a family of subroutines headed by a main subroutire; specialized subroutines for input, analysis, display, etc., may be added to the code to increase its capabilities. For examp'e, by adding a subroutine which reads data points from cards, aug of the operations avaiatile in the AUSS code may be applied to a series of discreet amplitudes punched in cards.

The ADSS code is stored on mapnetic lape and is operational on both the CDC-6600 and -7600 machines.

\section{Method of Operation}

The major operations performed by the ADSS code are identified by number, and any task within the capability of the program must therefore be requested by its assigned number, or "instruction number." Several operations require that additional numbers, besides the appropriate instruction number, must be supplied in the calling of that instruction. For example, the function which reads the label library for plotting is

\footnotetext{
I Sćhreiber, David and R. Vielleux, "A General Computer Code for Environmental Test Data Reduction on the CDC-6600 Computer," unpeblished.
} 
assignea instruction No. 1 , but must be called by using " $1 \mathrm{~N} 1$," where $\mathrm{N} 1$ is the number of labels to be read for each axis.

The instruction numbers (together with any required supplemental mimbers) which correspond to the sequence of operations requested by the user form the "instruction string." Thus, the entries of the instruction string control the logical execution of the code, and must be read by the program first. Each entry is punched in 15 format, with up to 16 entries on a card. A special sentinel, 99999, must be included as the last eniry in the instruction string. After reading the string, the main subroutine then interprets each instruction sequentially, executing the simple instructions itself and transferring control to the appropriate subroutines for the more complex operations.

Many of the operations (instructions) of the code require information not supplied by the instruction string in order to be executed. This information is read from supplemental data cards, which must be read in the exact order that the corresponding instruction numbers occur in the instruction string. Hence, if the first instruction of the instruction string is " 13 ," then the six label cards (three for each axis) to be read by that instruction must be placed immediately foilawing the set of instruction string cards in the input deck.

\section{Classes of Instructions}

\section{INITIALIZATION}

Several insiructions must be called first to set parameters which control the functioning of various other instructions.

instruction numbers in this class are:

$$
\begin{aligned}
& 1 \text { - read labels } \\
& 2 \text { - specify } X \text {-axis labels } \\
& 3 \text { - specify } \Psi \text {-asis labels } \\
& 4 \text { - channel numbering } \\
& 5 \text { - calibration scaling units } \\
& 6 \text { - ID label } \\
& 7 \text { - time code factor } \\
& 12 \text { - mumber of charnels } \\
& 14 \text { - size of data disk tile } \\
& 16 \text { - termination of job } \\
& 21 \text { - input device initialization }
\end{aligned}
$$

Before the first reading of digitized dat a, several instructions $x$ ust be called. First, the number of multiplexed channels (NCHANS) on the input device (usually magnetic tape) must be set by using instruction No. 12. The code is capable of processing up to 30 multiplexed data channels. Second, the digital tape unit or input disk file must be initialized by calling Instr. 21. Third, the ID label for diagnostic 
messages must be read using Instr: 6. Also, if applicable, the time code factor must be set by Instr. 7, and the size of the data disk file (initially 81000) altered using Instr. 14 .

Before scaling the data, the engineering units (ACOR values) which apply to the calibration pulse of each cinannel must be set by Instr. 5. Any plotting or processing of the data channels requires that the label library be read by Instr. 1, axis labels be designated by use of Instrs. 2 and 3 , and the channel numbers (ICOR van es) be assigned to each channel by Instr. 4.

T'he last instruction to be called, imnediately before the 99999 sentinel, should be No. 16, whicin provides the normal iermination of the job.

\section{DIGITAL DATA INPUT}

The multiplexed data is usuaily read directly from a magnetic tape. However, if the contents of the tape are transferred to a disk file prior to the use of this code, the data can be read irom that input disk fille.

Instruction numbers in this class are:

22 - rewind input derice

23 - space over data records

24 - space over data files

25 - backspace over data ́́iles

27 - unload lata tape

28 - destroy input disk file

32 - read digital data

34 - save data

The digitized data froduced by the $A / D$ converter is grouped into data records. Each record consists of 27 scans, 11 words per scan, and 36 binary bits per word. The 11 words $\vec{v}$ each scan consist of one time ford followed by 10 data words. The time word has the following bit pattern:

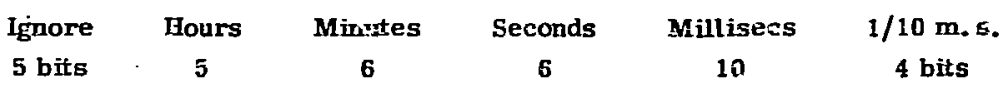

The 36 bits of each data word contain three 12-bit data points. Because two bits are ignored, the number of possille values each data point may assume is $2^{10}=1024$. When unpacked and converted to 60-bit data points, these values are interpreted decimally as -511 to 511 , inclusive.

The data records are grouped by end-of-file (EOF) marks, and the read unit must be positioned at the beginning of the data file to be read. To accomplish tinis, the input device may be spaced forward over data records (Instr. 23) or data files (Instr. 24), backspaced over data files (Instr. 25) or rewound (Instr. 22). Finally, Instr. 27 unloads the magaetic tape from the read unit, or if the input is from disk, the input disk file is destro; ad by Instr. 26. 
Instruction 32 searches the scans of successive data records unil the initial time word which is greater than or equal to the input begin-read-time is found. The average increment between the 27 time words of the record to which this first tims word belongs is computed, and then compared with each of the 26 increments, if iewer than three increments deviate more than $\mathbf{0 . 0 0 1}$ seconds from the average, the time-per-point (TPP) is computed (in seconds) by dividing the average time word increment by the number of data points sampled from each scan. Huwever, if three or mere errant increments are found, the next data record is used to compute TPP. The data points are read, unpacked, sampled, and stored, until the first time word greater than the input end-readtime (or an EOF mark) is encountered. If the EOP has not ceen reached, the input device is then spaced up to and over the EOF mark.

Each dugitized data record produces, after remopal of time words, 810 60-bit data points. Memory allocations are sufficient to store 25 recoris, or 20250 data points in the DATA array. If more than 25 records are to be stored, then the code automatically creates a disk file with a capacity of 81000 points, or 100 records. If created, this disk file will be autonatically destroyed when the job is terminated with Instr. 16. For lengthy spans of dat $=$, the sampling rate mist be used to limit the number of stored points.

Because each use of instr. 32 destrogs the previous contents of the DATA array. Instr. 34 may be uscd to eave the contents of any of the multiplexed channels. A disk tile (SA VEFILE) is automatically created to save the desired channels, and automatically destroyed when lnstr. 16 is called.

\section{CALIBRATION AND SCALING}

Instruction numbers in this class are:

35 - read calibration parameters

37 - calculate calibration parameters

38 - scale data

To convert the data foints from digital counts to their engineering units, the calibration parameters CALOW and CAL.PK must be set. This may be done by reading the calibration data file into the DAT $\mathcal{A}_{\text {array }}$ (nstr. 32), and then using Instrs. 36 or 37 to calculate CALOW and CALF'K. Horever, if no calibration signal is available, the parameters may be assigned values using Instr. 35 .

Once the parameters CALOW, CAI.FK, and ACOR (Instr. 5) are set, the test data may be read into the DATA array (Instr. 32) and scaled using Instr. 36. 


\section{DATA ANALYSIS AND MANIPULATION}

Instruction numbers in this class are:

39 - remove mean and/or linear trend

44 - cross-correlation

45 - Fouri. $r$ analysis

47 - taper data

48 - alter data by a constant

50 - weight spectral data (filtering)

53 - add or subtract channel pairs

55 - multiply or divide channel pairs

5 s - mitiply or divide spectral chanrel pairs

After the data is scaled, it may be necessary to pre-process it beiore performing any cross-correlation or Fourier analysis. The mean and/or linear trend is removed from the data by Instr. 39, and Instr. 47 tapers the tails of the data. The data can be altered by a constant value using Instr. 48, and pairs of channels are sombined arithmetically using Instrs. 53 and 55 .

The direct cross-correlation of specified channel pairs is performed $\mathrm{h}_{j}$ lnstr. 44. Instruction $\$ 5$ Fourier transforms the data, and if desired, the spectral results are eaved in disk illes, whose names are supplied by the user. If these saved spectral resulits are then read into the DAT A array (nstr. 31), further manipulativn is possible. Spectral channel pairs may je multiplied or divided by Instr. 56. This instruction may also be used to form the convolution or cross-correlation product, which when inverse transformed (Instr. 45) gives the indirect convolution r.s cross-correlation funstion. Finally, Instr. 50 weights the spectral data of specified channels, and when the weighted data is inverse transformed (Instr. 45), frequency filrering is performed.

\section{DATA DISPLAY}

Instruction numbers in this class are:

$$
\begin{aligned}
& 60 \text { - data printing } \\
& 61 \text { - set grid type } \\
& 62 \text { - set max. and min. axis values } \\
& 63-67 \text { - data plotting } \\
& 68 \text { - spectral flotting }
\end{aligned}
$$

At any stage of the data frocessing, the contents of the DATA array may be printed or plotted. Instruction 60 is used to print the contents of epecified chamnels (those with nonzero ICOR value) on the high speed printer (HSP). 
The CRT plotting of data channels is performed by linstrs. 63-67, and if the channels contain spectral data, they raay be plotted using Instr. 68. At any time, the type of grid being plotted may be altered by using Instr. 6i, and the maxirnum and minimum axis vaiues may be set by Instr. 62 .

All plots contain a header label consisting of the 10 label read by Instr. 6, and the channel number set by Instr. 4.

\section{DISK FLE TRANSPORT}

Instruction numbers in this class àre:

$$
\begin{aligned}
& 26 \text { - tratsports files to data tape } \\
& 29 \text { - destroys files } \\
& 39 \text { - demultiplexes chameis to files } \\
& 31 \text { - reads files ti channels }
\end{aligned}
$$

In addition to those disk files automatically created and nanied by the code le. g., Inst :s. 32 and 34), others, whose names are supplied by the user, may be needed, and aze called "user-named" disk files. These files may be created by Instr. 45, if saving the transformed results is requested, or by Instr. 30, which demuitiplexes data channela into disk flles. Instruction $30 \mathrm{may}$ also be used to perform progressive interpolntion on the contents of any data channel, by specifying the desired new time incrersent.

User-nawed spectral disk files may be transported between the disk and the data tape by lnstr. 26. This can be used to do additional filtering in the data, without needing to regenerate the spectrums.

The contents of user-named disk files can be read into specified channels using Instr. 31, whereby the previous contents of all data channeis are lost. Hence, any disk files to be processed togetiner must be read into channels using a single call to Instr. 31 .

The responsibility of destroying all user-named disk files belongs to the user (it is not done automatically), and is performed by Instr. 29.

\section{UTILITY AND DEBUG}

Instruction numbers in this class are:

$$
\begin{aligned}
& 13 \text { - repeat instructions } \\
& 17 \text { - non-terminal dump } \\
& 18 \text { - timing routine }
\end{aligned}
$$

The ADSS code is structured for production analysis, and much user time can be saved by writing, whenever possible, instruction loops into the instruction striag. 
Instruction 13 will execute a specified sub-string of instructions an assigned number of times, and requires the writing of the sub-string only once by the uger.

Instruction 18 can be called both t,efore and after a sub-string of instructions to calculate the time required for the execution of that sub-string.

When debugging, Instr. 17 should be used to print a memory dump on the HSP. Control will then be returned to the main subroutine, to continue execution.

\section{Instruction Descriptions}

INST RUCTION NO. 1 N 1

\section{Function}

Reads $\mathrm{N} 1 \mathrm{X}$-axis label cards, and Ni $\mathrm{Y}$-axis label cards, in that order, where $\mathbf{N} \mathbf{i} \leq 2 \dot{z}$.

\section{Format for Data Cards}

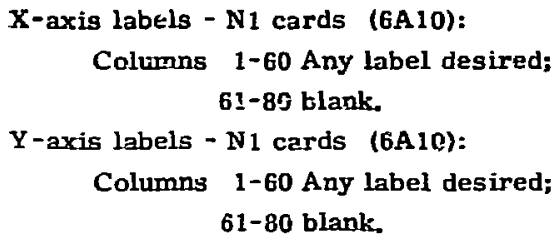

\section{Initiaĩization}

The labei library is initially blank.

\section{INST RUCTION NO. 2}

\section{Function}

Reads a data card specifying which of the $X$-axis labels nead by Instr. 1 are to be used with each channel being plotted. This number is called the IXT value for each channel.

Format for Data Card (30I2)

Each channel is allotted 2 columns on the data card in which the number of the $\mathrm{X}$-axis label for that channel is designated. 
Example: To assign the 4th, 2nd, and 10th X-axis labels to the 1st, 2nd, and 3rd channels, respectively, Instr. 2 is used with the c..ca card.

$\begin{array}{lrrrrrrr}\text { Columns } & 1 & 2 & 3 & 4 & 5 & 5 & 7 \ldots 80 \\ \text { LXT value } & & 4 & & 2 & 1 & 0 & \text { Blank }\end{array}$

Initialization

None required.

INST RUCT ION NO. 3

Function

Reads a data card specifying which of the $Y$-axis labels read by instr. 1 are to be used with each channel being plotted. This number is called the IYT value for each chanrel.

\section{Format for Data Card (3012)}

Eash channel is allotted 2 columns on the data card in which the number of the $Y$-ixis label for that channel is designated.

Example: To assign the 2nd, 3rd, and 8th $Y$-axis labels to the 1st, 2nd, and 3 rd channels, respectively, Instr. 3 is used with the data card:

$\begin{array}{lrrrrrrc}\text { Columns } & 1 & 2 & 3 & 4 & 5 & 6 & 7 \ldots 80 \\ \text { IYT value } & & 2 & & 3 & & 8 & \text { Blank }\end{array}$

$\underline{\text { Initialization }}$

None requized.

INST RUCT ION NO. 4

Function

Reads a data card specifying the channel number (or ICOR value) to be assigned to each channel. This number appeare on the heading of the plots, and also designates to several other instructions (e.g., 36, 45, 63) which channels, by their nonzero ICOR value, are to be processed. Negative ICOR values are not allowed. 
Each channel is allotted 2 columns on the data card in which the ICOR value for that channel is assigned.

Example: To assign the channel numbers 1, 2, and 5 to the 1st, 2nd, and 3rd channels, respectively, then Instr. 4 would be used, with the data card:

$\begin{array}{lrrrrrrr}\text { Columns } & 1 & 2 & 3 & 4 & 5 & 6 & 7 \ldots 80 \\ \text { ICOR value } & 1 & & 2 & & 5 & \text { Blank }\end{array}$

\section{Initialization}

None required.

\section{INST RUCTION NO. 5}

\section{Finction}

Reads, from one to four data cards, the ACOR value to be assigned to each channel. These values are in engineering units, and are used by Instr. 38 to scale the data.

\section{Format for Data Card(s) (8F10.0)}

As many as eight channels may be 2ssigned by each data card, and as many as iour data cards may be necessary to assign values to each multiplexed channel (NCHANS in number).

Example: If the three multiplexed channels have ACOR values $2000 \mathrm{~g}$ 's/pulse, $150.3^{\circ} \mathrm{F} /$ pulse, and $156 \mathrm{~mm} /$ pulse, respectively, then the data card would appear as:

$\begin{array}{llllc}\text { Columns } & 1-10 & 11-20 & 21-30 & 31 \ldots \ldots 80 \\ \text { ACOR value } & 2000 . & 150.3 & 156 . & \text { Blank }\end{array}$

\section{Initialization}

Instruction 12 must have been called to set the number of multiplexed channels (NCMANS). 


\section{INST RUCT ION NO. 6}

\section{Function}

Reads one data card containing a run identification label. This label appears as the heading for the piots, and in some diagnostics.

Format for Data Card (4AI0)

Columns 1-40 Any desired Label;

41-80 blank.

\section{Initialization}

The identification label is initially blank.

$$
\text { INST RUCTION NO. } 7 \text { N1 N2 }
$$

\section{Function}

Sets the tape time code correction factor to (N1/N2). The tape time code is multiplied by this factor to correct a record/playback speed discrepancy on the analogue time code.

\section{Initialization}

This factor is initially unity.

INST RUCTION NO. $12 \mathrm{~N} 1$

\section{Function}

Sets the number of multiplexed channels on the digital input tape or disk (NCHANS) equal to $\mathrm{N} 1$.

\section{Initialization}

NCHANS = 1 initially.

Note: $\mathbf{N} 1$ must be a divisor oĩ 30 . 
Function

The code executes $\mathrm{N} 1$ times the $\mathrm{N} 2$ instruction values (blanks included) that follow $\mathrm{N} 2$ in the instruction string. Nested repeat loops are allowed.

Enitialization

None required.

INST FUCTION NO. 14

\section{Function}

Reads a data card containing the length of the data disk file, which is automatically created if ever more than 20,250 data points (after sampling) are read in at one time.

\section{Format for Data Card (I6)}

The first 6 columns of the data card contain the disk file length, which must be a multiple of 810 , the number of 60-bit words from one $A / D$ record.

Example: The disk file is to have length 105300 words:

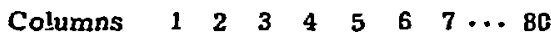

$$
\begin{aligned}
& \begin{array}{llllllll}
\text { Entry } & 1 & 0 & 5 & 3 & 0 & 0 & \text { Blank }
\end{array}
\end{aligned}
$$

\section{$\underline{\text { Initialization }}$}

The length is initially 81000 words.

$$
\text { INST RUCTION NO. } 16
$$

\section{Function}

This is the normal method of terminating the program.

\section{Operation}

The system routine EXIT is called after any disk files automatically created and named by the code are destroyed. 


\section{Initialization}

None required.

INST RUCTION NO. 17

\section{Function}

An octal dump of memory is made on HSP output, and nommal operation is resumed.

\section{Operation}

The system rout ine OCDUMP is called, and is currently available only on the CDC-6600 computer.

\section{Initialization}

None required.

INST RUCTION $1 \%$ U. 18

\section{Function}

Prints the elapsed machine time charged (in seconds) since the last call to this instruction, and is used to time the execution of any instruction string.

\section{Operation}

The system routine 00TIM is called.

\section{Initialization}

The first call to this instruction initializes the timing routine, and the elapsed time is computed on subsequent calls.

\section{INST RUCTION NO. 21 N1}

\section{Function}

Loads (assigns) the digital data tape and sets its density, or opens the input det: disk file, depending on the value of $\mathbf{N} 1$. The vault number of the tape or the name cit the disk file is read from a data card. 


$$
\begin{array}{ll}
N_{1}<0 & \text { for input data disk file. } \\
N_{1}=0 & \text { for 200 BPI data tape. } \\
N_{1}=1 & \text { for } 556 \text { BPI data tape. } \\
N_{1}=2 & \text { for } 800 \text { BPI data tape. }
\end{array}
$$

\section{Format for Data Card (A10)}

Whether using an input tape vault number, or disk file name, both wilust be right justified in the first 10 columns of the data card.

Example: The input data is recorded at $800 \mathrm{BPI}$ on the tape with vault number AC317. Then the instruction 212 is used, and the data card appears as:

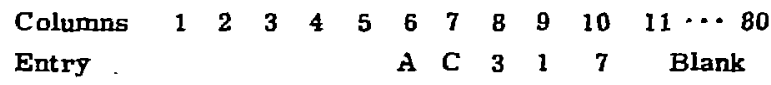

Initialization

This instruction must be called prior to any data read or tape/disk handling instructions.

\section{RST RUCTION NO. 22}

\section{Function}

Rewinds the digital data input device (tape or disk).

\section{Initialization}

Instruction 21 must have been called.

INST RUCTION NO. 23

\section{Function}

Reads a data card specifying the number of data records to be skipped, and then skips that number of records on the digital input device.

\section{Format for Data Card (I5)}

$\begin{array}{lll}\text { Columns } & 1-5 & \text { Number of records to be skipped. } \\ 6-80 & \text { Blank }\end{array}$




\section{Initialization}

Instruction 21 must have been called.

INSTRUCTION NO. 24

\section{Function}

Reads a data card specifying the number of data files to be skipped, and then skips that number of files on the digital input device.

Format for Data Card (I5)

Columns 1-5 Number of files to be skipped.

6-80 Blank.

Initialization

Instruction 21 must have been called.

INST RUCTION NO. 25

Function

Reads a data card specifying the number of data files to be backspaced over, and then backspaces over that number of files on the digital input device.

Format for Data Card (15)

Columns 1-5 Number of files to be backspaced over.

6-80 Blank.

\section{Initialization}

Instruction 21 must have been called. 
INST RUCTION NO. 26 N1

\section{Function}

Transports user-named spectral files between the disk and digital data tape according to $\mathrm{N} 1$ :

$$
\begin{aligned}
& \text { N1 }>0 \quad \text { Transfers } N 1 \text { files from disk to data tape. } \\
& \text { N1 } 0 \text { Transfers }-\mathrm{N} 1 \text { files from data tape to disk. }
\end{aligned}
$$

In either case, data card(s) are read containing the disk file names.

\section{Format for Data Card(s) (8A10)}

Up to 8 file names per card, and up to 25 file names may be used. The names are right justified in successive 10 column fields.

Example: If the spectral file SNORT 1 is to be saved on the data tape, then the instruction 261 is used with data card:

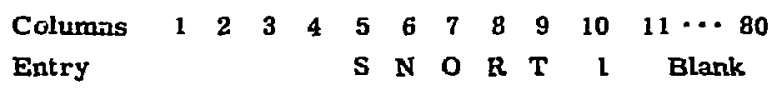

\section{Operation}

1. If $\mathrm{N} 1>0$, the individual disk files are opened, their contents are written, with EOF marks between them, on the data tape, and the files are closed.

2. If $\mathrm{N} 1<0$, the individual disk files are created, filled with successive files from the data tape, and then closed.

\section{Initialization}

Instruction 21 must have been called, and the tape moved to the desired location (beyond digitized data). Only files written by this instruction may be transferred from the data tape in this manner.

\section{INSTRUCTION NO. 27}

\section{Function}

Unloads the digital input tape from tape reader.

\section{Initialization}

Instruction 21 must have been called. 


\section{INST RUCTION NO. 28}

Function

Destroys the digital input disk file.

\section{Initialization}

Instruction 21 must have been called.

$$
\text { INSTRUCTION NO. } 29 \mathrm{~N} 1
$$

Funetion

Reads data card(s) containing the names of N1 user-named disk files, and then destroys these files. The files should be demultiplexed data or spectral files, whose names the user supplied when they were created.

\section{Format for Data Card(s) (8A10)}

Each of the N1 file names should be right justified in a 10 column field; up to 8 names per card, and a maximum of 25 names total.

Example: To destroy the spectral file SNORT 1, use Instr. 29 1, with the data card:

$$
\begin{array}{lllllllllllll}
\text { Coluinn } & I & \Xi & 3 & 4 & 5 & 6 & 7 & 8 & 9 & 10 & 11 & -80 \\
& & & & S & N & 0 & \mathbb{R} & T & 1 & \text { Blank }
\end{array}
$$

\section{Initialization}

None required.

$$
\text { INST RUCTION NO. } 30 \text { N } 1
$$

\section{Function}

Demultiplexes $\mathrm{N} 1$ channels and stores each in a separate user-named disk file. The channel numbers and disk fize names are read from $\mathrm{N} 1$ data cards. 
Format for Data Card(s) (A10, A10,2A10,A6, 4X, [5, [5, F10,0)

N1 data cards required; each has the form:

$\begin{array}{rrl}\text { Critumns } & 1-10 & \text { Disk file name (right adjusted in field). } \\ 11-20 & \text { Data type (optional). } \\ 21-40 & \text { Event name (optional). } \\ 41-46 & \text { Station name (optional). } \\ 47-50 & \text { Blank. } \\ 51-55 & \text { Channel mumber. } \\ 56-60 & \text { Process ing status (must be 10 if spectral data, } \\ & \text { otherwise optional). } \\ 61-70 & \text { Time increment (must be positive to alter increment, } \\ & & \text { Blherwise optional). }\end{array}$

Example: To create the disk file SNORT $\mathrm{l}$ and store in it the (non-spectral) contents of channel 3, Instr. $30 \quad 1$ is used, and the following data card is sufficient:

$\begin{array}{llllllllllllll}\text { Columns } & 1 & 2 & 3 & 4 & 5 & 6 & 7 & 8 & 9 & 10 & 11-54 & 55 & 56-80 \\ \text { Entry } & & & & & \text { S } & \text { N } & 0 & \text { R } & \text { T } & 1 & \text { Blank } & 3 & \text { Blank }\end{array}$

\section{Operation}

Performs the following steps $\mathrm{N} 1$ times:

Reads data card, creates the specified disk file, demultiplexes the contents of the specified channel, performs progressive interpolation on the data if a new time increment is reciusted fand data is nonspectral), stores the data in the disk file, and closes it.

Only one channel may be stored in any one file at a time.

\section{Initialization}

None required.

INSTRUCTION NO. 31 N1

\section{Function}

Stores specified portions of the contents of $\mathrm{N} 1$ user-named disk files into $\mathrm{N} 1$ separate multiplexed channels. The $\mathrm{N} l$ file names, channel numbers, read intervals, and sampling rates are read from $\mathrm{N} 1$ data $\operatorname{card}(s)$. 
Format for Data Card(s) (A10, 15, 415, 415, 15)

N1 data :ards required; each has the form:

\begin{tabular}{|c|c|c|}
\hline \multirow[t]{6}{*}{ Columns } & $1-10$ & \\
\hline & $11-15$ & Channel number. \\
\hline & $16-35$ & $\begin{array}{l}\text { Begin read mark - four } 5 \text {-column integers expressing } \\
\text { either time in hours, minutes, seconds, and tenths } \\
\text { of milliseconds, or irequency in Hertz, and talths of } \\
\text { milli-Hertz (last two fields isnored). }\end{array}$ \\
\hline & $36-55$ & $\begin{array}{l}\text { End read mark-four } 5 \text {-column integers expressing } \\
\text { either time or frequency as above. }\end{array}$ \\
\hline & $56 \sim 60$ & Sampling rate. \\
\hline & $61-80$ & Blank. \\
\hline
\end{tabular}

Operation

Performs the following process $\mathrm{N} 1$ times:

Reads data card containing the name of a file, a read interval, a sampling rate, and the number of a channel to be filled. The file is opened, the contents read over the specified interval at the sampling rate, and stored in the designated channel. The ifile is then closed.

The previous contents of all channels is lost when this instruction is called.

If the files contain spectral data, the number of points read in is always of the form $2^{n}+2$, for some positive integer $n$.

Initinlization

NCHANS must be preset.

INSTRUCTION NO. 32

\section{Function}

Reads a data card containing a sampling rate, and the endpoint times of a read interval. Using the corresponding endpoint time words of the digital data file, the data points in that interval are then read, unpacked, sampled, and stored (in multiplex form) in the DATA array. A time per point (in seconds) is computed, and the input and actual time interval endpoints are printed on the HSP. 
Format for Data Card $(1515,415,15)$

\begin{tabular}{|c|c|c|}
\hline Columns & $1-20$ & $\begin{array}{l}\text { Begin read time - four 5-column integers representing } \\
\text { hours, minutes, seconds, and tenths of milliseconds. } \\
\text { End read time-same format as above. }\end{array}$ \\
\hline & $41-45$ & Sampling rate. \\
\hline & $46-80$ & \\
\hline
\end{tabular}

Operation

If more than 20,250 data points are to be stored, then a disk fibe of length 81,000 (or whatever length set by Instr. 14) is created, and all data pcints are stored in it. finy excess points to this file are lost.

The sampling rate determ ines the ratio of the number oi data points read to the number that are stored in the DATA array. Thus, if the sampling rate is specified as unity, every data point read will be stored. After completion of the read, the input device is spaced up to and over the next EOF mark.

\section{Initialization}

Instruction 21 and, if necessary, Instrs, 12 and 14 must have been called. The input tape or disk must be positioned at the desired file before reading.

INST RUCTION NO, 34 N1 N2 N3

\section{Function}

Manipulatee and transfers DATA channels, in multiplex form, between DATA array and a disk file (SAVFFILE). The options for transferring chanels are:

\begin{tabular}{|c|c|}
\hline $\mathrm{N} 1=1$ & Channel N2 of DATA sent to channel N3 of SAVEFILE. \\
\hline $\mathrm{N} 1=2$ & Channel N2 of SAVEFILE sent to charrel N3 of DATA. \\
\hline $\mathrm{N}_{1}=\mathbf{3}$ & $\begin{array}{l}\text { Channel N2 of DATA and channel N3 of SAVEFILE are } \\
\text { switched. }\end{array}$ \\
\hline $\mathrm{N} 1=4$ & Channel N2 of DATA sent to channel N3 of DATA. \\
\hline
\end{tabular}

Operation

On the first call to Instr. 34, unless $\mathrm{N1}=4$, the disk file SAVEFILE is automatically created. The mumber of points in each channel stored there is recorded. Then, when later transferring a SAVEFILE channel to a DATA channel, either the SAVEFILE channel or all DATA channels may be truncated to equalize their lengths. 
Initiaization

None required.

RST RUCTION NO, 35

suretion

Roads data cards which specify the calibration parameter values (in digital counts) to se used in scaling the data. The parameter names are CALOW and CALPK, and each thanru: (NCHANS in number) must have values assigned.

Format isr Data Cards

CA.LOW values (8F 10.0):

Each channel is allotted 10 columns for its value. Up ro eight values per eard, and NCHANS total values.

CAI PK values (BF 10.0):

Same as above.

Initialization

NCHANS must be set.

NSTHUCTION NO. 36 NI N2 N3

ivunction

Estabilishes the calibration parameters (CALOW and CALPK) for those channels in: through $\mathrm{N}$ : whose ICOR valus is nunzero, according to the value of $\mathrm{N} 3$ :

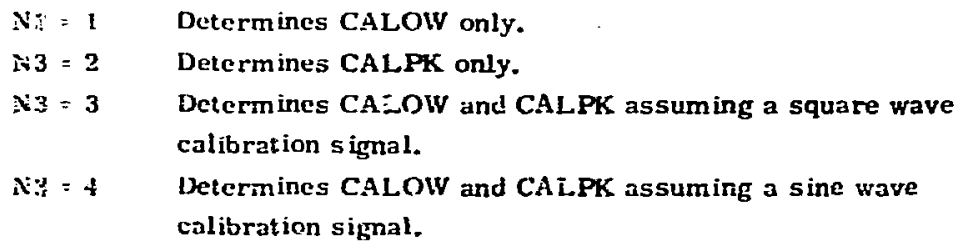

$\therefore$ Fist it the caliblation sigmal (in digital counts) for each processed channel

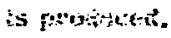


For N3 = 1 and N3 = 2, the arithmetic mean of the channel is computed and stored in the appropriate parameter.

For $\mathrm{N} 3=3$, and $\mathrm{N} 3=4$, the maximum ( $\mathrm{AMAX}$ ) and minimum (AMIN) data values of the channel are found, then CALPK = AMAX, and CALOW $=(A M A X+A M T N) / 2$.

Initialization

The calibration signals for the appropriate channels must be in the DATA array. ICOR values must be set.

\section{INST RUCT ION NO. 37 N1 N2 V3}

This instruction is the same as Instr. 36, except no plots of the calibration signals are produced.

INSTRUCTION NO. 38 N1 N2 N3

\section{Function}

Scales, into engineering units, the digital data of those channels N1 through N2 whose ICOR value is nonzero, according to the value of N3:

$$
\begin{array}{ll}
\text { N3 }=-1 & \text { YSC }=\frac{\text { ACOR }}{\text { CALPK-CALOW }} \times(\text { Y-YAVG })+\text { CONST. } \\
\text { N3 }=1 & \text { YSC }=\frac{\text { ACOR }}{\text { CALPK-CALOW }} \times(\mathrm{Y}-\mathrm{YAVG}) . \\
\text { N3 }=-2 & \text { YSC }=\frac{\text { ACOR }}{\text { CALPK-CALOW }} \times(\mathrm{Y}-\mathrm{CALOW})+\text { CONST. } \\
\text { N3 }=2 & \text { YSC }=\frac{\text { ACOR }}{\text { CALFK-CALOW }} \times(\mathrm{Y}-\mathrm{CALOW}) . \\
\text { N3 }=-3 & \text { YSC }=\frac{\text { ACOR }}{\text { CALFK-CALOW }} \times(\mathrm{Y})+\text { CONST. } \\
\text { N3 }=3 & \text { YSC }=\frac{\text { ACOR }}{\text { CALPK-CALOW }} \times(Y) .
\end{array}
$$

where:

$\mathbf{Y}=$ raw data in digital counts,

YSC $=$ scaled data in engineering units,

$A C O R=$ values set by Instr. 5 ,

CALPK and CALOW = values set by Instrs. 35,36 , or 37 , YAVG = average of first 10 data points, and CONST $=$ values read from data card(s). 
Needed only for N3 negative, in order to set CONST value for each channel. Up to 8 values per card; a total of NCHANS values are required.

Initialization

NCHANS, ACOR, ICOR, CALPK, CALOW values must have been set.

$$
\text { INSTRUCTION NO. } 39 \text { N1 N2 N3 }
$$

\section{Function}

Preconditions the data of those channels N1 through N2 whose ICOR value is nonzero, according to the value of N3:

$$
\begin{array}{ll}
\text { N3 }=1 & \text { Removes (subtracts) the arithmetic mean. } \\
\text { N3 }=2 & \text { Removes the linear trend. } \\
\text { N3 }=3 & \text { Removes both the mean and linear trend. }
\end{array}
$$

\section{Operation}

For N3 = 1 the mean is computed, and subtracted from the data.

For N3 = 2 and N3 = 3, a linear least squares fit of the data is performed, to determine the values $M$ and $B$ of $Y=M X+B$. Then if

$$
\begin{array}{ll}
\text { N3 }=2 & M(X-T / 2) \text { is subtracted, where } T=\text { length of } \\
\text { time interval (in seccads) of data, and if }
\end{array}
$$

\section{Initialization}

ICOR values must have been assigned.

$$
\text { INST RUCTION NO. } 44 \text { N1 N2 }
$$

\section{Function}

Performs cross-correlation (by the direct method) of $\mathrm{N} 1$ channel pairs, with N2 lags in each direction, and plots the $\mathrm{N} 1$ resulting functions versus time. A data card specifying the $\mathbf{N} 1$ channel pairs is read. If a zero-lag auto-correlation is requested, the result is printed on HSP, but not plotted. 
The N1 channel pairs are listed, with each channel in a two column field. A maximum of $\mathrm{N} 1$ = 15 pairs is allowed.

Example: To cross-correlate channels 1 and 4 and auto-correlate channel 3, both with 10 lags in each direction, the instruction 44210 is used with data card:

$\begin{array}{lllllllllll}\text { Columns } & 1 & 2 & 3 & 4 & 5 & 6 & 7 & 3 & 9 & -80 \\ \text { Entry } & & 1 & & 4 & & 3 & & 3 & \text { Blank }\end{array}$

\section{Operation}

If $(A, B)$ is an input channel pair. and $N$ is the number of data points in each channel, then the $2(\mathrm{~N} 2)+1$ lag products are determined as follows:

$$
\begin{aligned}
& \operatorname{LAG}(S)=\sum_{t=1}^{N-S} \operatorname{DATA}_{A}(t) \operatorname{DATA}_{B}(t+S) \quad \text { for } 0 \leq S \leq N 2 \text {, } \\
& L A G(S)=\sum_{t=1}^{N-S} \operatorname{DATA}_{A}(t+S) \operatorname{DATA}_{B}(t) \quad \text { for }-N 2 \leq S \leq-1
\end{aligned}
$$

A maximum of N2 $=4999$ lags is allowed in each direction.

\section{Initialization}

The ICOR, XXT, and IYT values for the first member of each channel pair are used for plotting, and must be preset.

$$
\text { INSTRUCTION NO. } 45 \text { N1 N2 N3 N4 N5 N6 }
$$

\section{Function}

Performs Fourier analysis on those channels N1 through N2 whose ICOR value is nonzero, according to the value of N3:

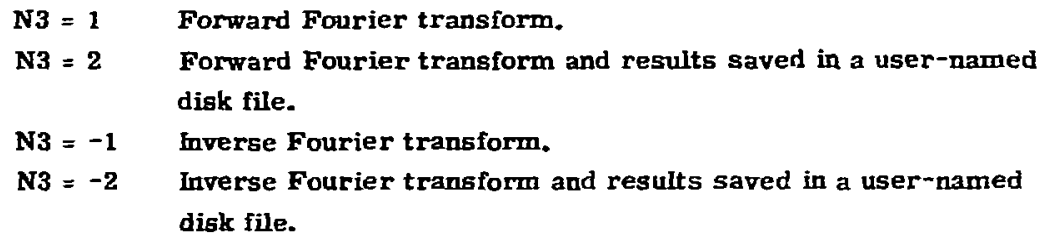


The number of complex points transformed is $2^{n}$, for some $n \leq 13$ : if $N 4=0, n$ is computed by the code; if $\mathrm{N} 4>0$, then $\mathrm{n}=\mathrm{N} 4$.

That portion of the power spectrum (forward transform) or impulse response (inverse transform) defined over the interval N5 to N6 units is plotted.

If saving the results is requested (N3 $=2$ or $\mathrm{N} 3=-2$ ), then for each channel processed, a data card naming a disk file is read (one channel per disk file).

Format for Data Card(s) (A10, A10,2A10, A6, 4X, 15, I5)

Required only if $\mathrm{N} 3=2$ or N3 $=-2$; then one data card is needed for each channel processed.

$\begin{array}{rll}\text { Columns } & 1-10 & \text { File name (right adjusted in field). } \\ 11-20 & \text { Data type (optional). } \\ 21-40 & \text { Event nane (optional). } \\ 41-46 & \text { Station name (opt ional). } \\ 47-50 & \text { Blank. } \\ 51-55 & \text { Channel number. } \\ 56-60 & \text { Processing status (must be 10 if spectral } \\ & \text { results, otherwise optional). } \\ 61-80 & \text { Blank. }\end{array}$

\section{Operation}

Uses the Cooley-Tukey Fast Fourier Transform algorithm (FCOOL).

For the forward transform, enough zeros are added to the data of each processed channel, $X(j)$, to given $N=2^{n}$ (complex) points, where $n \leq 13$. The $N$ complex spectral values, $A(m)$, are calculated as follows.

$$
A(m)=\sum_{j=0}^{N-1} x(j) w_{N}^{-m j} .
$$

where $m=0, \ldots, N-1$, and $w_{N}=\exp (2 \pi i / N)$.

Because the data is real, the power spectrum, $|A|^{2}$, folds about its midpoint, and only $2^{n-1}+i$ complex values $\left(2^{n}+2\right.$ array words) are used for plots and saving, in amplitude-phase pairs, on disk. The avrsage energy $\left(\frac{1}{\mathrm{~T}} \sum|A|^{2} \Delta \omega\right), D C$ and maximum power components, and frequency increment $\left(\frac{l}{T}\right)$ are printed.

For the inverse transform, the number of amplitude-phase pairs in each processed channel is expected to be of the form $2^{n-1}+1\left(2^{n}+2\right.$ array words), where $\mathbf{n} \leq 13$. The last pair is assumed to correspond to the folding frequency. The $\mathbf{N}=2^{\mathbf{n}}$ 
complex points of the spectrum, $A(m)$, are then generated by symmetry, and the $N$ real values, $X(j)$, of the inverse transform are computed:

$$
X(j)=\frac{L}{N} \sum_{m=0}^{N-1} A(m) w_{N}^{m j}, \text { where } j=0, \cdots, N-1
$$

Initialization

IXT, IYT, and ICOR values must be preset.

$$
\text { INST RUCTION NO. } 47 \text { N1 N2 N3 N4 }
$$

\section{Function}

Uses a cosine taper to smooth the tails of those chemels N1 through N2 whose ICOR value is nonzero. The first N3\% and the last $(100-N 4) \%$ of the selected channels are tapered.

\section{Operation}

If $N \%$ of the left tail of a channel with time interval length $T$ is to be tapered, the point $x(t)$ is weighted by multiplying by

$$
c(t)=\frac{1}{2}\left(1-\cos \left(\frac{t x}{N T}\right)\right)=\sin ^{2}\left(\frac{t \pi}{2 N T}\right), \text { where } 0 \leq t \leq N T \text {. }
$$

Similarly, the last $(100-M) \%$ of the channel is weighted by

$$
c(t)=\frac{1}{2}\left(1-\cos \left(\frac{(T-t) \pi}{(1-M) T}\right)\right)=\sin ^{2}\left(\frac{(T-t) \pi}{2(1-M) T}\right), N T \leq t \leq T \text {. }
$$

\section{Initialization}

ICOR values must be preset. 


\section{Function}

Alters by a constant the data of those channels $\mathrm{N} 1$ through $\mathrm{N} 2$ whose ICOR value is nonzero, according to the value of N3:

$$
\begin{array}{ll}
\text { N3 }=1 & \text { Multiplies by a constant. } \\
\text { N3 }=2 & \text { Adds a constant. }
\end{array}
$$

The constants are read from data cards.

\section{Format for Data Card(s) (8F10.0)}

Each channel (NCHANS in number) must be assigned a constant, and each is allotted 10 columns on the data card for that purpose. Up to eight channels are assigued values on each data card.

\section{Initialization}

ICOR values must be preset.

$$
\text { INSTRUCTION NO. SU N1 N2 }
$$

\section{Function}

Weights the spectral data of those channels $\mathrm{N} 1$ through $\mathrm{N} 2$ whose ICOR value is nonzero. The weighting function is generated using the Dolph-Chebyshev (D-C) function, and an idea! filter specified on data cards. The power spectrum and impulse response of the weighting function are plotted.

\begin{tabular}{|c|c|c|}
\hline \multirow[t]{5}{*}{ Columns } & $1-5$ & $\begin{array}{l}\text { Type of ideai filter (1 - lowpass, } 2 \text { - highpass, } \\
3 \text { - bandpass, } 4 \text { - difierentiate). }\end{array}$ \\
\hline & $6-10$ & No, of points (NOP) used to define ideal filter. \\
\hline & $11-15$ & $\begin{array}{l}\mathbf{N} \text {, where } P=2^{N} \text { is the number of points to be } \\
\text { generated by the Dolph-Chebyshev function. }\end{array}$ \\
\hline & & Pass band width of D-C function (Nyquists). \\
\hline & $26-80$ & Blank. \\
\hline
\end{tabular}

Format for Data Cards

Parameter Card $(15,15,5,15$, F10.0) 


\section{Ideal Filter Card(s) (3F8,0, 3F8.0, 3F8.0)}

The ideal filter is defined by NOP triplets (frequency, amplitude, and phase), each with format 3F8.0, and up to 3 triplets per data card. For standard pass bands, only two triplets are needed, to specify the corners of the pass band.

Note: If the ideal filter type number 4 (difierentiator) is specified, this instruction expects columns 6-10 to contain a zero (NOP $=0$ ), and 므 ideal filter cards are read.

\section{Operation}

The weighting function is generated by using the " $5-T$ 's" method." Additional information concerning the use of this instruction is given by Denny. 3

\section{Initialization}

ICOR values must be preset. Channels must contain spectral data.

$$
\text { INSTRUCTION NO. } 53 \text { N1 }
$$

\section{Function}

Sums or subtracts the data of specified channel pairs, according to tbe value of N1:

$$
\begin{aligned}
& \text { N1 }>0 \text { Addition of channel pairs. } \\
& \text { N1 }<0 \text { Subtraction of channel pairs. }
\end{aligned}
$$

A data card is read specifying the N1 (or -N1) pairs of data channels. The resulting values replace the data of the first channel of each pair.

\section{Format for Data Card (3012)}

Example: To compute the sum of channels 2 and 3 and store it in channel 3 , the instruction 531 is used, with the data card:

$\begin{array}{lllllll}\text { Columns } & 1 & 2 & 3 & 4 & 5 & -80 \\ \text { Entry } & & 3 & & 2 & \text { Blank }\end{array}$

\footnotetext{
${ }^{2}$ Helms, Howard D., "Nonrecursive Digital Filters: Design Methods for Achieving Specifications on Frequency Response," ItEE Trans. on Audio and Electronics, AU-16, 336-342 (1968).

${ }^{3}$ Denny, M. D. . "Digitally Filtered Rayleigh Waves as a Y ield Indicator," to be published.
} 
Initialization

None required.

INST RUCTION NO. $55 \mathrm{~N} 1$

Function

Multiplies or divides the data of speciried channel pairs, according to the value of $\mathrm{N}$ 1:

N1 $>0$ Multiplication of channel pairs.

N1 $<0 \quad$ Division of channel pairs.

A data card is read, specifying the N1 (or -N1) pairs of data channels. The resulting values replace the data of the first channel of each pair.

Format for Data Card (30I2)

Example: To divide channel 1 by channel 2 (the results to channel 1) and channel 5 by channel 2 (the results to channel 5 ), Instr. $55-2$ is used, with the following data card:

$\begin{array}{lllllllllll}\text { Columns } & 1 & 2 & 3 & 4 & 5 & 6 & 7 & 8 & 9 & -80 \\ \text { Entry } & & 1 & & 2 & & 5 & & 2 & \text { Blank }\end{array}$

\section{Operation}

If division by zero is attempted, the result is set equal to the previous quotient (or zero, if the previous result is not available).

\section{Initialization}

None required.

INSTRUCTION NO. 56 N1 N2

\section{Function}

Multiplies of divides the spectral contents of $\mathrm{N} 1$ specified channel pairs, according to the value of $\mathrm{N2}$ :

$$
\begin{array}{ll}
\text { N2 }=-1 & \text { Division of spectral channel pairs. } \\
\text { N2 }=1 & \text { Multiplication of spectral channel pairs. }
\end{array}
$$




$$
\begin{array}{ll}
\text { N2 }=2 & \text { Convolution product of spectral channel pairs. } \\
\text { N2 }=3 & \text { Cross-correlation product of spectral channel pairs. }
\end{array}
$$

The resulting spectral values replace the data of the first channel of each pair. A data card specifying the $\mathrm{N} I$ channel pairs is read.

\section{Format for Data Card (30I2)}

Example: To multiply channels 3 and 4, and store the results in channel 4 , the instruction 5611 is used, with data card:

$\begin{array}{lllllll}\text { Columns } & 1 & 2 & 3 & 4 & 5 & -80 \\ \text { Entry } & & 4 & & 3 & \text { Blank }\end{array}$

A maximum of $\mathrm{N} 1=15$ pairs is permitted on the card.

\section{Operation}

If the spectral contents of channels $I$ and $J\left(A_{I}(n)\right.$ and $\left.A_{J}(n)\right)$, respectively, are to be combined, the following results corresponding to values of N2, are stored in channel I:

$$
\begin{array}{ll}
\text { N2 }=-1 & A_{1}(n) / A_{J}(n) . \\
N 2=1 & A_{I}(n) A_{J}(n) . \\
N 2=2 & (-1)^{n} A_{I}(n) A_{J}(n) . \\
N 2=3 & (-1)^{n} \overline{A_{I}(n)} A_{J}(n),
\end{array}
$$

where the bar indicates the complex conjugate.

If division by zero is attempted (divisor has zero amplitude), the result is sat equal to the previous quotient (or zero, if the previous quotient is not available).

\section{Initialization}

The channels must contain spectral data.

$$
\text { INST RUCTION NO. } 60
$$

\section{Function}

Prints on the HSP the contents of all channels whose ICOR value is nonzero.

\section{Initialization}

ICOI values must be preset. 
INST RUCTION NO. 61 N 1

\section{Function}

Specifies which type of grid is to be used for plots, according to the value of N1:

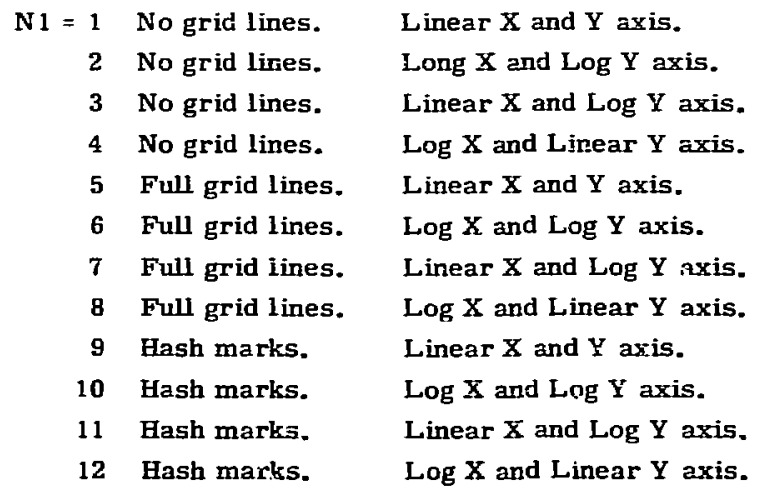

\section{Operation}

The grid parameter can be set and reset only by this instruction, and affects all plot instructions.

\section{$\underline{\text { Initialization }}$}

The grid type is preset to full grid lines and linear $X$ and $Y$ axis $(N 1=5)$.

$$
\text { INST RUCTION NO. } 62 \text { NI }
$$

\section{Function}

Determines, according to the value of $\mathrm{N} 1$, how the minimum ar $\perp$ maximum values for the $\mathrm{X}$ and $\mathrm{Y}$ axes of the plots are to be defined:

N1 $=0$ The min. and max, ralues for both axes will be determined from the data to be plotted. No. data cards are read.

$N 1=1$ Reads the min. and max. values for the $X$-axis; those for $Y$-axis are determined from data.

$\mathrm{N1}=2$ Reads the $\mathrm{min}$, and max. values for the $\mathrm{Y}$-axis; those for $\mathrm{X}$-axis are determined from data.

N1 = 3 Reads the min, and max. values for both axes. 


\section{Format for Data Cards}

Required if $\mathrm{N} 1=1$ or $\mathrm{N} 1=3$ :

a. X-axis minimum values (8F10.0);

Each channel (NCHANS in number) must be assigned a value, and has

10 columns of the data card allotted for this purpose. Up to eight channels may be assigned values per card.

b. X-axis maximum values (8F10.0).

Required if $\mathrm{Nl}=2$ or $\mathrm{Nl}=3$ :

a. $\mathrm{Y}$-axis minimum values (8F10.0);

b. $\mathrm{Y}$-axis maximum values $(8 \mathrm{~F} 10.0)$.

\section{Operation}

The minimum and maximum values set by lnstr. 62 affect only those plots generated by Instrs. 63-67, and will be used until this instruction is called again. If the minimum and maximum values of a channel are left blank on the data cards, these values will be determined from the data of that channel.

\section{Initialization}

The minimum and maximum values are initially deterinined from the data (i. $\epsilon_{\text {. }}$ N1 $=0)$. NCHANS must be preset.

\section{INST RUCTION NO. 63}

\section{Function}

Plots, against time, the contents of al those channels whose ICOR value is nonzero. A separate plot is generated for each of the selected channels.

\section{Initialization}

IXT, IYT, and ICOR values must be preset.

INSTRUCTION NO. 64 N1 N2 N3

\section{Function}

Plots, against the contents of channel N3, the contents of those channels N1 through $\mathrm{N} 2$ whose 1 COR value is nonzero. 
Initi:

IXT. IY $i$, and ICofl vilues must be preset.

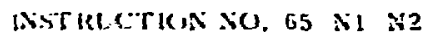

Franction

The same as instr. 63, except thet unly an interval, defined by $\mathrm{N}_{1} \mathrm{~g}$ to $\mathrm{N} 2 \%$ of the whit time of each riannol is plotter.

$\underline{\text { Initializations }}$

IXT, 12T, and ICOK values must be preset.

INSTRECTLON NO. 66 NI N2 N3 N4 N5

Function:

Plots, against the contents of channel N5, the interval N1\% to N2\% of the contents of those channels $\mathrm{N} 3$ through $\mathrm{NA}$ whose ICOR value is nonzero.

Initialization

IXT, NT. and iCOR values must be preset.

INST RUCT ION NO. 67 N1

Function

Slots, against time, the contents of $\mathrm{N} I$ specified channels on one CRT frame. A data card specifying the $N 1$ channels is read.

Format for Data Card (3012)

A maxirum of 30 channels may be listed, each in a two column field.

Example: To plet both channels 3 and 5 versus time on one frame, instruction

672 is used with chata card:

$\begin{array}{lllllll}\text { Columns } & 1 & 2 & 3 & 4 & 5 & -80 \\ \text { Entry } & & 3 & & 5 & \text { Blank }\end{array}$




\section{Initialization}

The ICOR, DXT, and IYT values for the first channel specified are used, and must bc preset.

\section{INST RUCT ION NO. 68}

\section{Function}

Plots, against frequency, the power spectrum (decibels) and phase shift (degrees) of all those spectral channels whose ICOR value is nonzero. Two plots are generated for each of the selected channels.

\section{Lnitialization}

The channels must contain spectral data. ICOR values must be preset. 


\section{Appendix}

\section{INDEX TO INST RUC"T IONS}

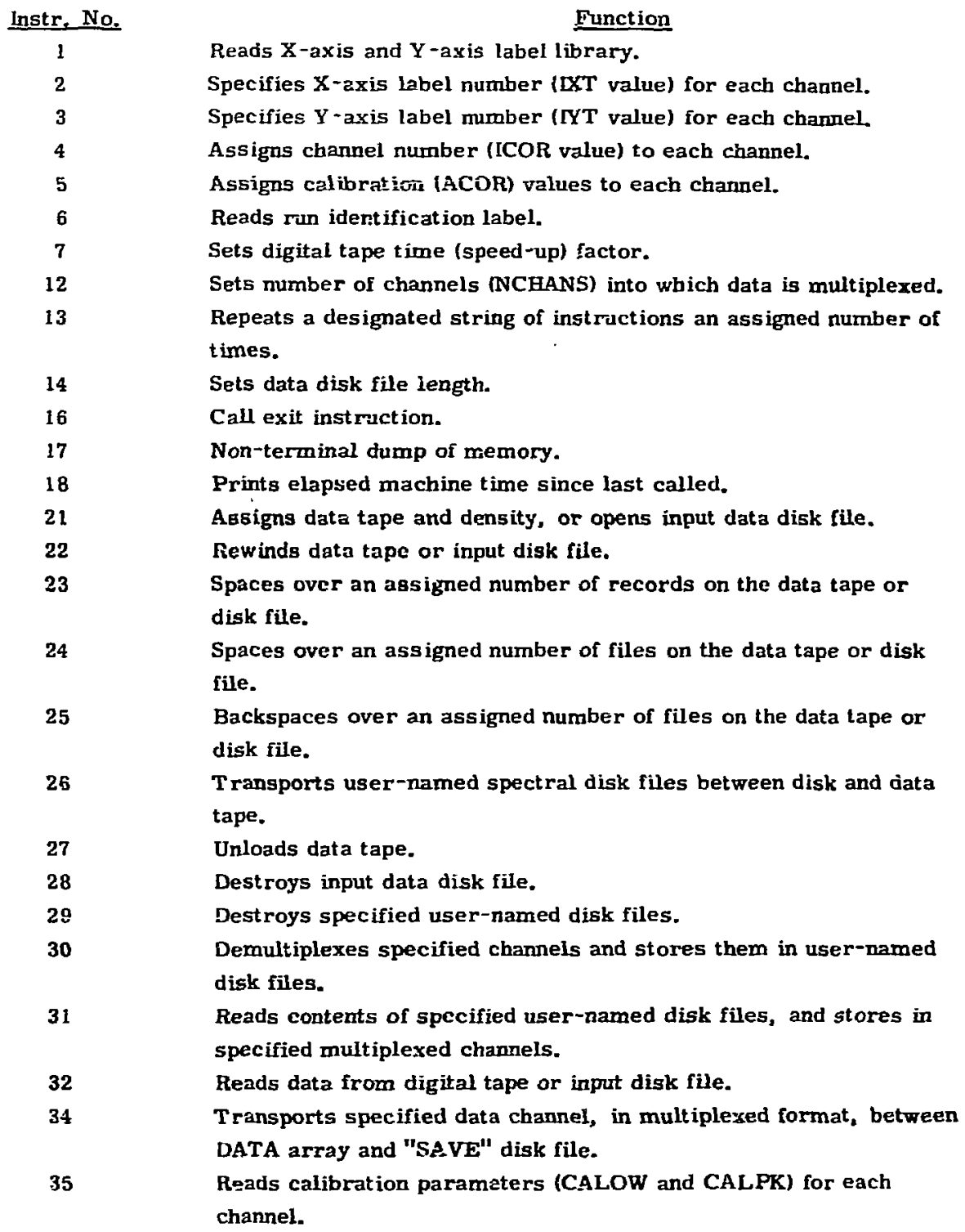


Instr. No.

38

39

44

45

47

48

50

53

55

56

60

61

62

63

64

65

66

67

58

Function

Computes calibration parameters (CALOW and CALPK) from calibration data file, and plats calibration signal.

Same as Instr. 36, but no plcts.

Scalés data into engineering units by an assignued method.

Removes mean and/or linear trend from data.

Computes and plots the cross-correlation function for specified channel pairs.

Performs Fourier analysis on specified channels, saving the result in user-named disk fules if desired.

Smooths an assigned percentage of the data, using a cosine taper.

Multiplies data by, or adds data to, a specified constant.

Weights the contents of specified spectral channels, using the Dolph-

Chebyshev function, and a specified ideal filter.

Sums or subtracts specified channel pairs.

Multiplies or divides specified cbannel pairs.

Multiplies or divides specified spectral channel pairs.

Prints contents of specified channels.

Sets the type of grid to be used for plots.

Reads max. and min. for $X$ - and $Y$-axis of plots.

Plots specified channels versus tine.

Plots specified chanuels versus another channel.

Same as Instr. 63, except an assigned percentag" of each channel is plotted.

Same as Instr. 64, except an assigned percentage of each channel is plotted.

Plots specified channels versus time on one CRT frame.

Plots the power spectrum and phase shift of specified spectral

channels versus frequency.

\section{SAMPLE PROGRAM}

Tables 1 and 2 describe the contents of the digitized magnetic tape (vault number AC319) to be analyzed. The sample program will read, scale, plot, auto-correlate, Fourier analyze, and filter the A/D channel number 1. The sine wave calik ation signal is in data file number $I$, and the event signal will be read from the courth data file of the tape.

Figure 1 shows a numbered listing of the 35 cards of the input deck used to run this job. 
Table 1. F. M. tape schedule.

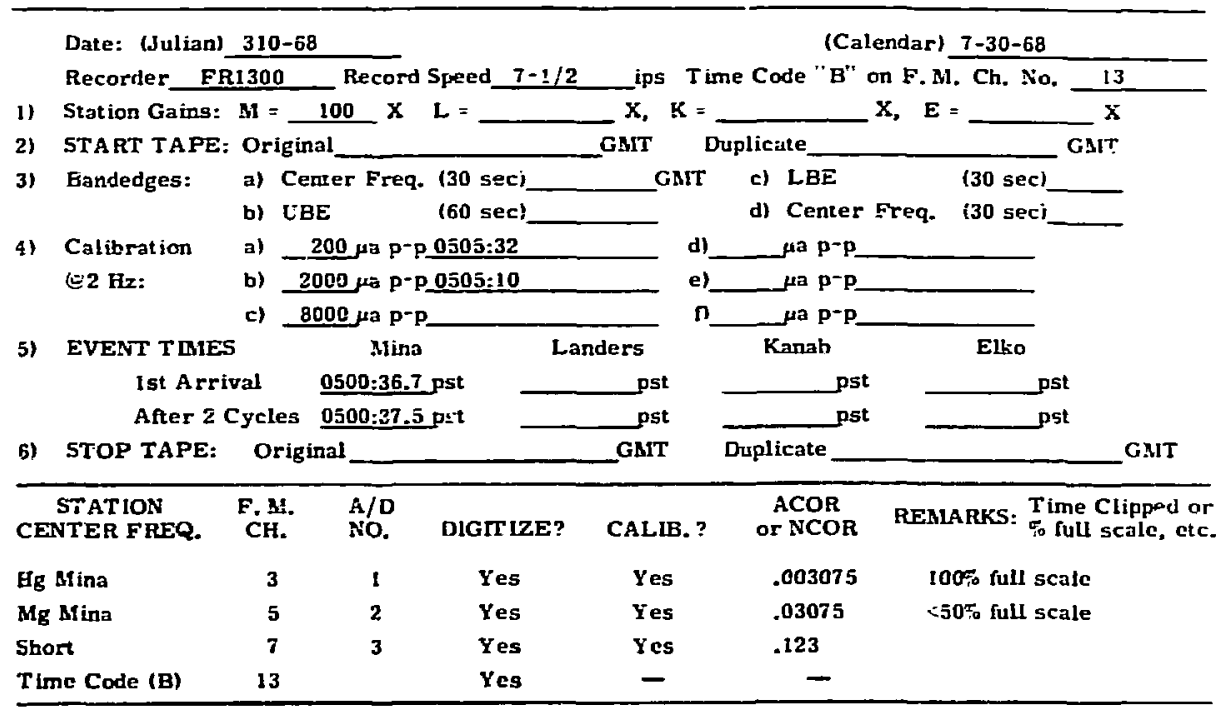

Table 2. Digital tape (Vault AC319).

\begin{tabular}{|c|c|c|c|c|}
\hline \multirow[t]{2}{*}{ DATE: (Julian) } & $310-68$ & ; (Calendar) & \multicolumn{2}{|c|}{$7-30-68$} \\
\hline & Basic A/D & $24 \quad \mathrm{kc} ; \mathrm{A}$ & asing Fr & 1000 Hz. \\
\hline DATA DESCRIPTION & TSTART & TEND & FILE & $\begin{array}{c}\text { of } \\
\text { RECORDS }\end{array}$ \\
\hline Mina High Gain Calibration & $0505: 32$ & $0505: 37$ & 1 & 38 \\
\hline Ignore & & & 2 & 892 \\
\hline Ignore & & & 3 & 38 \\
\hline Mina High Gain Event & $0500: 36.7$ & 0505:00 & 4 & 1958 \\
\hline
\end{tabular}

\section{Explanation of Input Cards}

The input deck has three sections: the control cards (Nos, 1-4), the instruction string cards (Nos. 5-10), and the supplemental data cards (Nos. 11-35). 


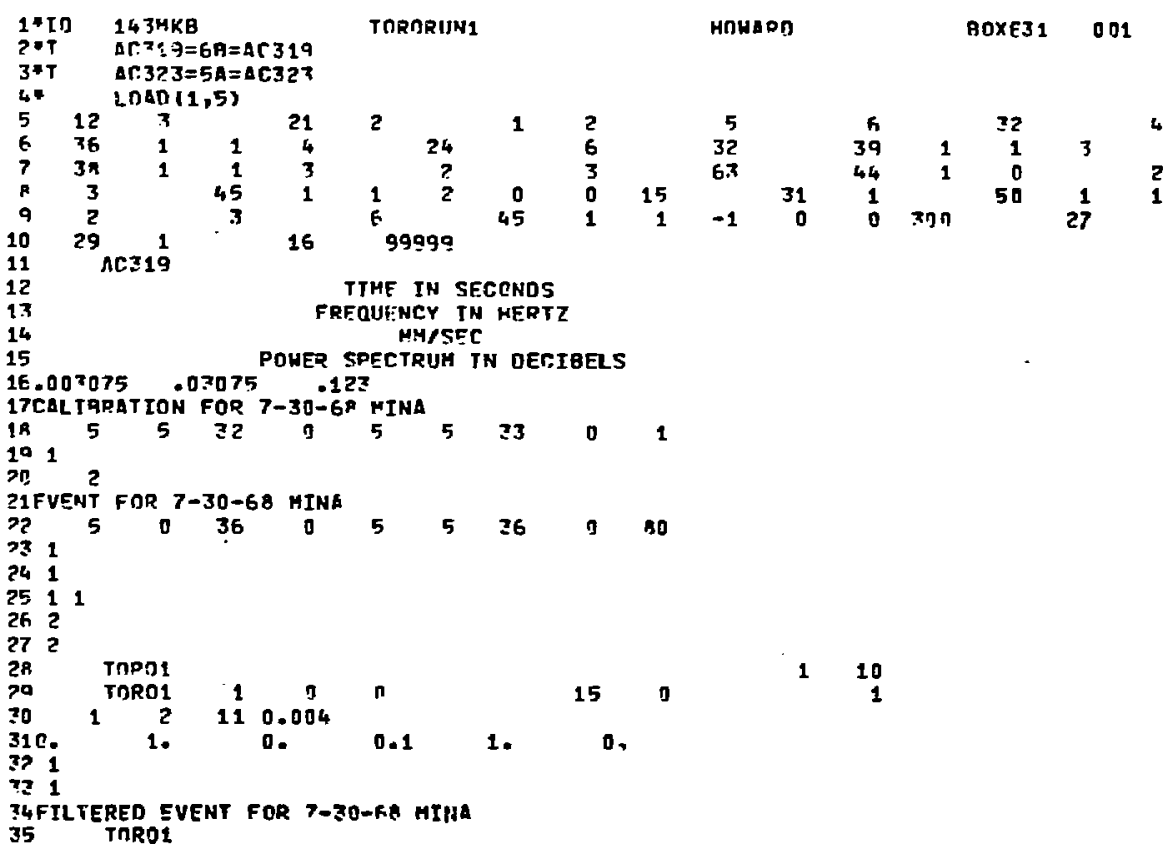

Fig. 1. Listing of the 35-card deck used in the sample run.

Control Cards

Card No. 1

Identifies the user account, problem name, user name, and box number.

2 Specifies the vault number of the data tape.

3 Specifies the vault number of the tape on which the ADSS code is stored.

4 Reads the ADSS code into memory from the specified tape.

\section{Instruction String and Supplemental Data Cards}

Fach of the instructions has been space delimited to assist in its identification. The CRT output produced by this job is shown on the pages following the instruction descriptions. 
Instruction

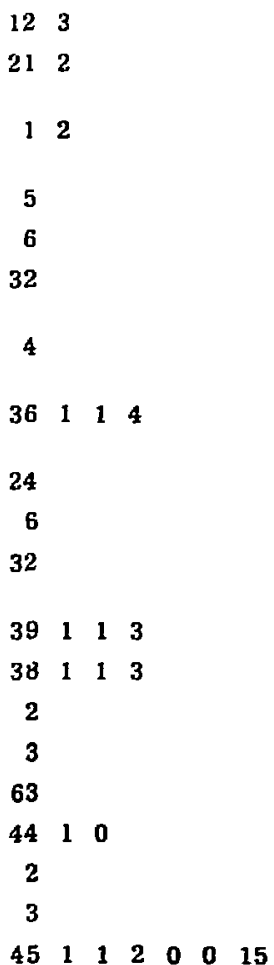

$31 \quad 1$

$50 \quad 1 \quad 1$
3

6

$\begin{array}{lllllll}45 & 1 & 1 & -1 & 0 & 0 & 300\end{array}$

27

291

16

99999
Qperation Performed and Supplemental Data Cards Required

Sets the number of multiplexed channels to 3 .

Reads the vault number (card No. 11) of the data tape, loads the tape, and assigns its density as $800 \mathrm{bpi}$.

Reads $2 \mathrm{X}$-axis labels (card Nos. 12 and 13 ), and $2 \mathrm{Y}$-axis labels (card Nos. 14 and 15).

Reads ACOR values (card No. 16) for the 3 channels.

Reads run ID (card No. 17).

Reads and stores data (caitbration signal), using the read interval (1 sec) and sampling rate (1) (card No. 18).

Sets the ICOR values (card No. 19)-only chanmel $l$ is to be processed.

Sets CALOW and CALPK values for channel 1, and plots calibration signal (Fig. 2).

Spaces tape to data file number 4 (card No. 20).

Reads ID (card No. 21).

Reads and stores data (event signal), using the read interval (5 min) and sampling rate (80) (card No. 22).

Removes mean and linear trend from channel 1.

Scales channel 1 .

Designates $X$-axis label No. 1 for channel $I$ (card No, 23).

Designates $Y$-axis label No. 1 for channel 1 (card No. 24).

Plots channel 1 versus time (Fig. 3 ).

Auro-correlates channel 1, with zero lags (card No. 25).

Resets DXT values (card No. 26).

Resets IYT values (card No. 27).

Fourier transforms thiane! $l_{\text {, plots }}$ its power spectrum (Fig. 4), and saves the spectrum in a disk file named TOROI (card No. 28).

Reads the entire spectrum in the disk file TORO1 into channel 1 (card No. 29).

Weights channel 1 .using a low-pass ideal filter $(0, .1)$, with zero phase shift (card Nos. 30 and 31 ), and plots the impulse response and power spectrum of the weighting function (Figs, 5 and 6).

Resets IXT values (card No. 32).

Resets IYT values (card No. 33).

Reads ID (card No. 34)

Inverse Fourier transforms channel 1 , and plots the resulting (filtered) signal (Fig. 7).

Unloads input tape.

Destroys the disk file TORO1 (card No. 35).

Terminates job.

Terminates instruction string. 

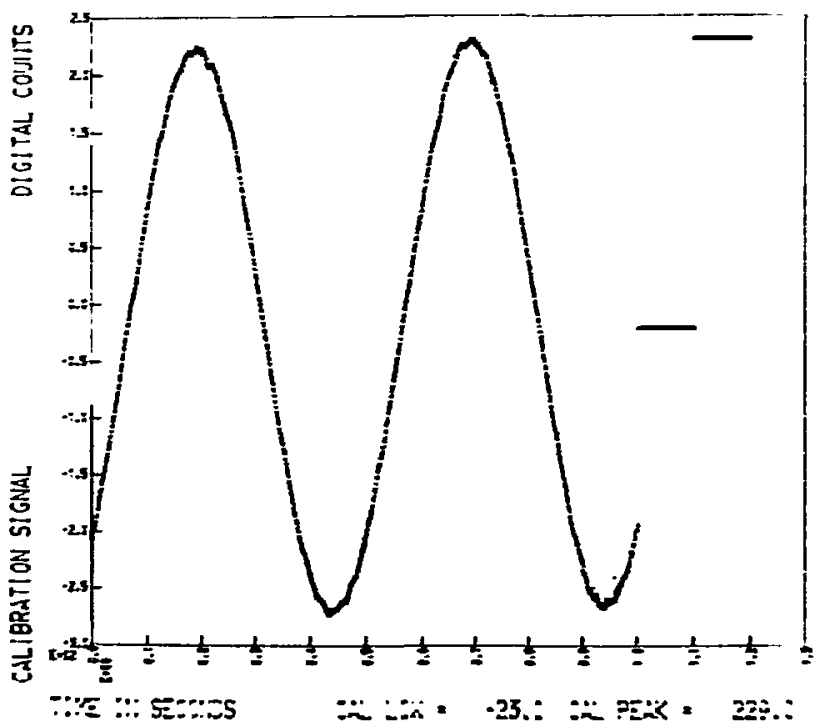

Fig, 2, Plot of calibration signal; instruction is "36 $134 . "$ Ever 60 7-50-60 AIL 재는

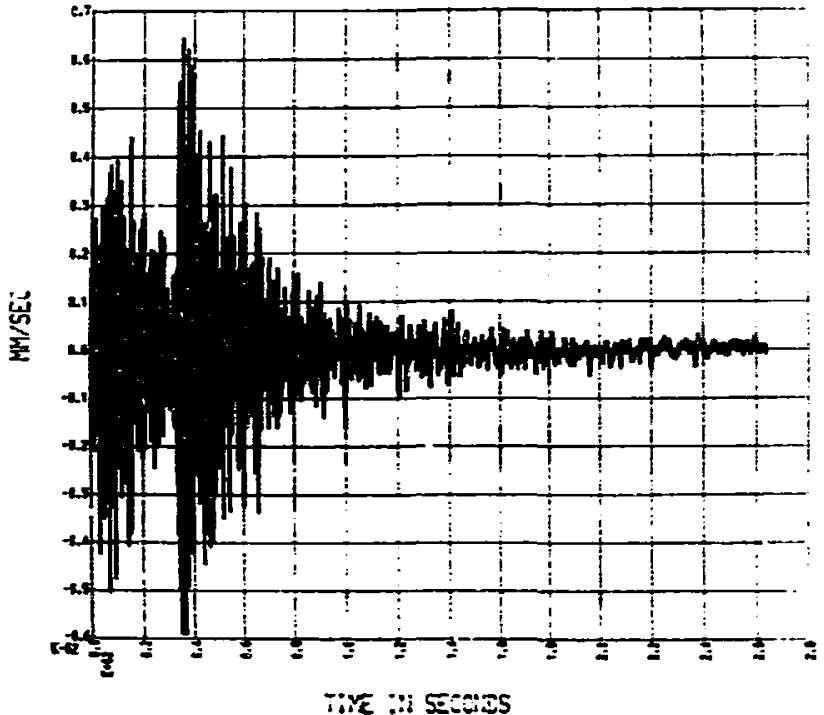

Fig. 3. Plot of channel 1 vs time; instruction is "63." 


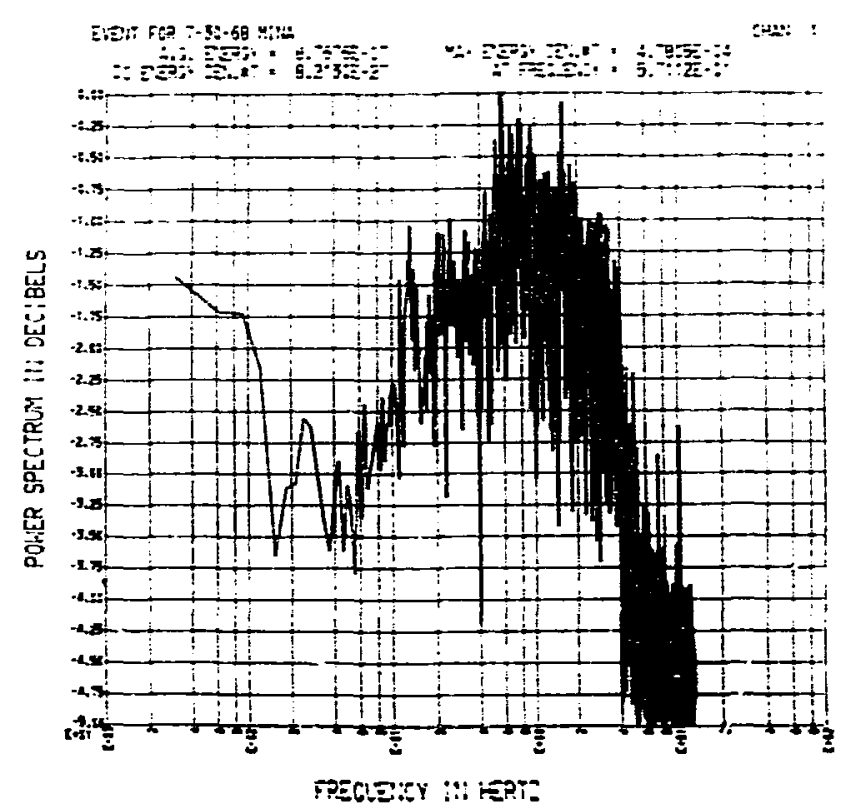

Fig. 4. Plot of power spectrum of channel 1 ; instruction is "45 I 12

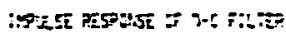
:ise: :

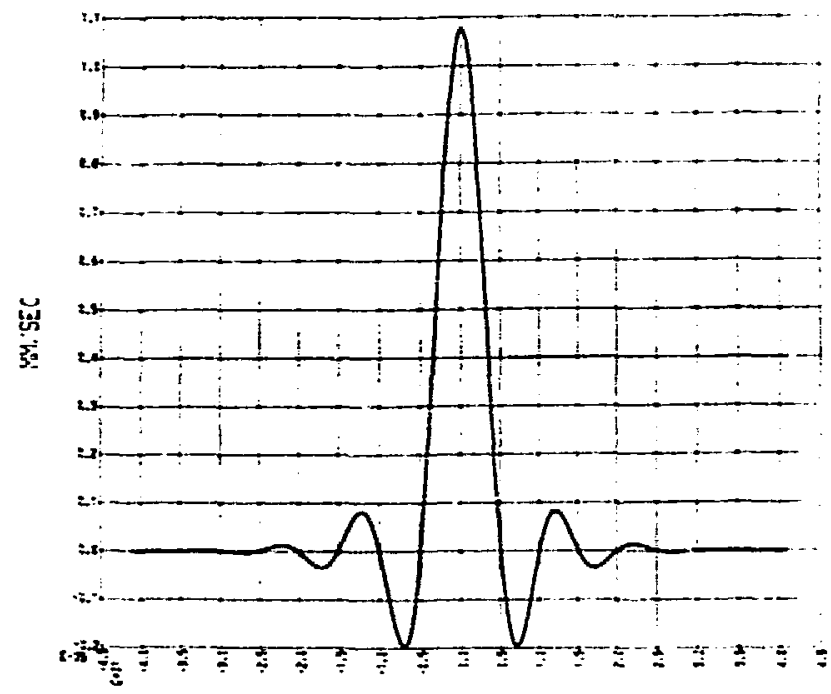

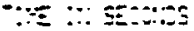

Fig. 5. Impulse response of the weighting function; inst ruction is "50 11 ." 


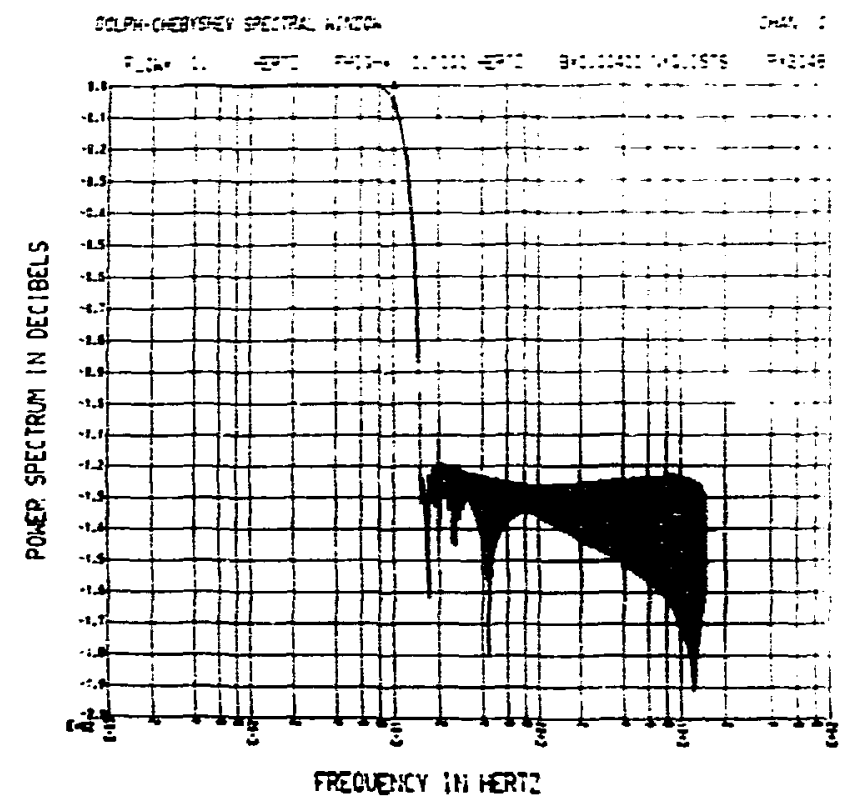

Fig. 6. Power spectrum of the weighting function: instruction is "50 1 1."

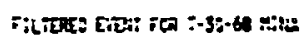

tHe: :

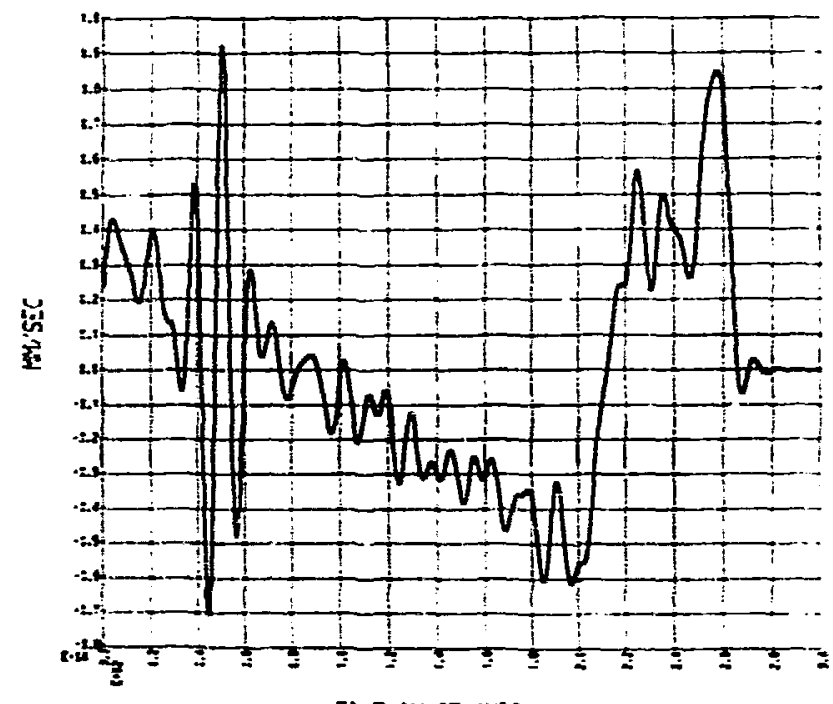

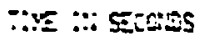

Fig. 7. Filtered signal resulting from Fourier transform of channel 1; instruction is "45 $1110-100300$. 
The variables defined below are those contained in the COMMON blocks. These variables zerve as the only means of communication among most of the subroutines in the cuve. All other variables appearing in the main subroutine and the other subrout ines are only temporary working variables, and will not be discussed here.

ACOR

ALPHUN

AMIN

AMAX

CALOW

CALFX

DATA.

DATAFILE

FINC

LA PLOT

ICNT

ICOK

IDADSK

INST

INST $R$

IPLSET

ISADSK

IX'Y

IST'

N I PLLR

NBIIPTS

NCHANS

NDADSK

NLNGTE

NMISK

Nout'

NSA ULAT

NWW()TKK

OMEGIUN
Array of cnlibration pulse levels. Set by Instr. 5.

Array of units (seconds or Herty) corresponding to the first data point of euch chimnel.

Array of minimum data values.

Array of maximum data valuea.

Array of calibration pulse low values. Set by Instrs, 35, 36, or 37.

Array of culibration pulse pesk values. Set by Instrs. 35, 36, or 37 .

Data storage array.

Contalns the nume of the data disk flle automatically created if the DATA array cannot accommodate all the data.

Frequency increment (Hertz).

Parameter whose value determines type of grid to be plotted. Set by Inst $x$, 61 .

Counter containing the location within the INST IR array of the instructien currently being executed by the code.

crray of channel numbers. Set by instr. 4.

Sintinel indicating the status of the data disk rile: IDADSK $=0$, no data disk file; IDADSK $=1$, data disk file created, but not currently used; IDADSK $=2$, data disk file contains data for current run.

Current instruction being executed.

Arre $y$ containing the instruction string.

Determines how the max. and $\mathrm{min}$, axis values are defined for plo'ting. Set by Instr. 62.

Sentinel indicating the status of the save disk file (SAVEFILE). Same valus: as IDADSK.

Array of $X$-axis label numbers. Set by instr. 2.

Arruy of $X$-axis label numbers. Set by Instr. 3.

Sumpling rate apecified when reading data.

Length of DATA array.

Number of multiplexed channels. Set by Instr. 12.

Number of data points stored in data disk file; used only when IDADSK = 2.

Size of data tisk file. Set by instr. 14.

Number of ditil points in DATA array; not used if IDADSK $=2$.

Logical unit number of devlee for printed output.

Arrily of sampling ritus.

Length of Wollk array.

Array of units (soconde or flettal corpesponding to the last data point of eatch channel. 
SAVEFILE Contains the name of the save disk file automatically created if data is saved by using Instr. 34 .

TPP Time per point iseconds).

WORK Array which provides temporary working space.

XID Array containing the run ID label. Set by Instr. 6.

XLAB Array containing the $X$-axis labels. Set by Inst $r .1$.

XSCALE Time code scaling factor. Set by Instr. 7.

YLAB Array containing the Y-axis labels. Set by Instr. 1.

\section{SUBROUT INES}

The subroutines which comprise the ADSS code are of two types: utility and specialized.

\section{Utility Subroutines}

Certain operations which are common to more than one subroutine have been converted into separate subroutines.

ADDSKIO Transfers data points between the DATA array and either the data disk file or the save disk file.

AMIMX Finds the min, and max, values of any specified irray.

FCOOL Performs the Cooley-Tukey algorithm (Fast Fourier Transform) on any specified array.

MST RPT Performs the plotting on the CRT.

\section{Specialized Subroutines}

The remaining subroutines each perform a specific task, and are not used by more than one other subroutine. All, except those listed below, have names of the form SUBXX, where $\mathrm{XX}$ is the number of the corresponding instruction. (For instance, Instr. 39 calls the subroutine SUB39).

CALAD

CATWDS

DCWIND

GRANGE

PLTPT

PRINT

SAVDAT

SCALE

TADATA
Calculates calibration parameter values (Instrs. 36 and 37). Used by TADATA to unpack the digital time words.

Used by SUB50 to generate spectral weights by the " $5-T$ ' $s$ " method. Used by DCWIND to generate the ideal filter using Lagrangian interpolation. (E1.1-002).

Sets parameters for call to MST RPT, to plot data.

Outputs data on the HSP (instr. 60).

Saves DATA charnels (instr. 34).

Scales data (Instr. 38).

Feads digitized data (Instr. 32). 
Each of the disk files created by Ins:rs. 30 and 45 requires the user to supply information, iacluding the file name, to the corje. These data, along with parameter vit is kept by the code, are timen written as a "Header" record of the disk file. This iftarder record is used to identify thr content 5 of the user-named disk file, and is written in a format which allows the use $=$ to display the Header information on a teletype inachine.

The first ten characters of the Header record form an inter-record word (IRW) usted by the aystem, and the following 120 characters contain the Header information.

\begin{tabular}{|c|c|c|}
\hline \multirow[t]{14}{*}{ Character } & $1-10$ & Inter-record word \\
\hline & $11-30$ & Data type $(A \mid 0)$ \\
\hline & $21-23$ & Hlənk \\
\hline & $24-91$ & Event nime $(A \mid 0, A 8)$ \\
\hline & $42-44$ & Blank \\
\hline & $45-50$ & Stat ion name (AG) \\
\hline & $51-55$ & Channel number $(15\}$ \\
\hline & $56-60$ & Processing status (15) \\
\hline & $61-68$ & Number of data points (19) \\
\hline & $69-70$ & Skip \\
\hline & $71-82$ & Begin unit (F12,4) \\
\hline & $93-57$ & End unit $([15.4)$ \\
\hline & $198 \cdot 103$ & Sampling tate (f6) \\
\hline & $10 ;-117$ & Unit incroment (E14,5) \\
\hline & $118-130$ & Skip \\
\hline
\end{tabular}

To tlispity ind, if desired, to alter the contents of the firsder record, the user may rill tix: Nis utility routine from the celetype. The kicader information is listed in the s:trut: orte: its it is stcred in the disk file: data type, cvent name, station name, Ahamnel nuniber, provessing status, number of data points, begin unit, end unit, satuplitig rate:, :in'l unit increment. An end-of-file sentinel denotes the end of the lleabler recorit.

An exaniple is slewwn in Fig. 4 . The data prints are written into the disk file using a 2-argument buffer operatien, and are stered in 10,000-word blacks. 


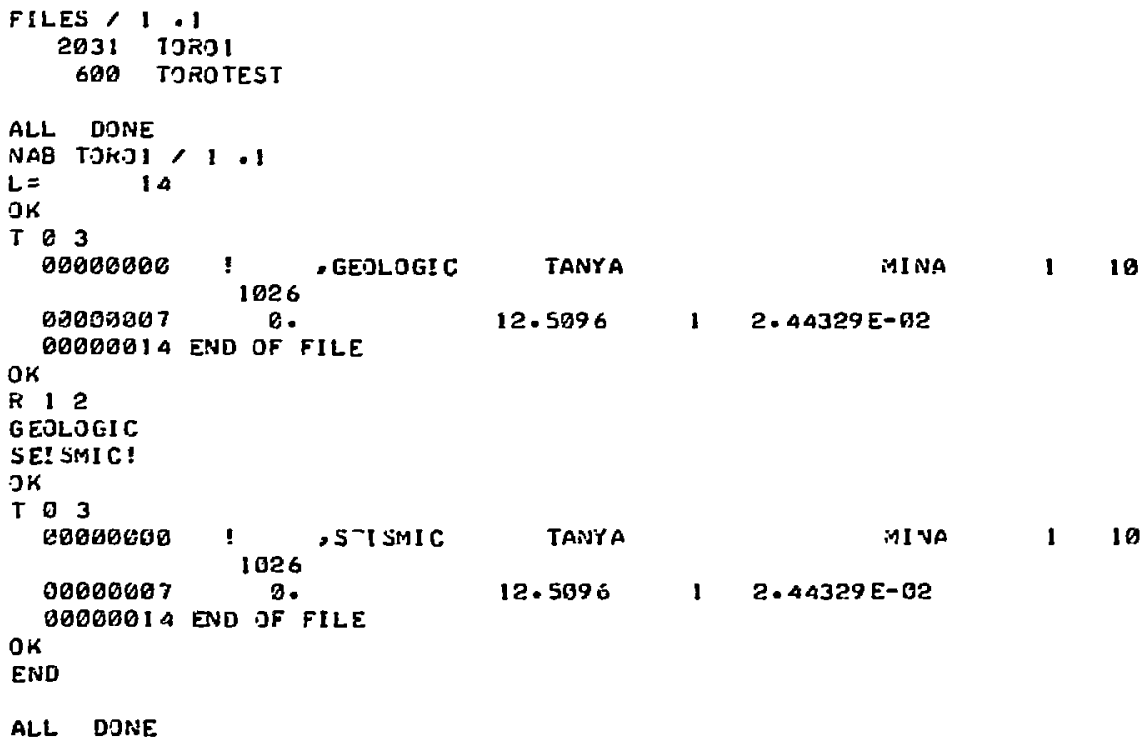

ALL DONE

Fig. 8. Altering the contents of the Header record using the NAB utility routine. 


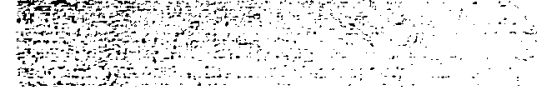

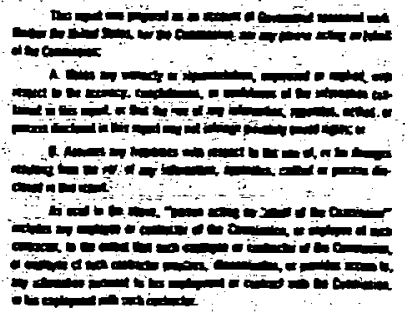

Printed in USA. Available from the National Technical

Information Center, National Bureau of Standards,

U. S. Department of Commerce, Springtield, Virginia 22151 Price: Printed Copy \$3.00; Microfiche \$0.65. 